\title{
OS DIREITOS DOS PACIENTES COM CÂNCER: A INEFICIÊNCIA DO ESTADO E O PAPEL HUMANITÁRIO DO ESTUDANTE DE DIREITO EM SUA EXPLICITAÇÃO
}

\section{THE RIGHTS OF PATIENTS WITH CANCER: AN INEFFICIENCY OF THE STATE AND THE HUMANITARIAN ROLE OF THE STUDENT OF LAW IN ITS EXPLANATION}

\author{
Dinah da Silva Rodrigues ${ }^{1}$ \\ Graziela Tavares de Souza Reis ${ }^{2}$
}

\section{RESUMO}

A Constituição Federal de 1988 garante a todos os cidadãos em seu art. 196, o direito à saúde, incumbindo ao Estado o dever de criar políticas de acesso universal e igualitário a todos os serviços que se fizerem necessários à sua manutenção. Todavia, há determinados grupos que são desassistidos, mesmo que hajam legislações específicas que tratem do assunto, como os pacientes com câncer. A partir do diagnóstico, a Lei nำ 12.732, de 22 de novembro de 2012, garante ao paciente com câncer que seu tratamento se inicie em no máximo 60 dias, além de outros direitos que lhe são conferidos. Não obstante, mesmo com tais garantias o Estado se negligencia, retirando dessas pessoas os direitos mais básicos, na maioria dos casos, por desconhecimento dos próprios pacientes de que possuem direitos que lhe são próprios.Nesse viés, destaca-se a importância dos estudantes de direito, que por meio de projetos de extensão universitária, podem explicitar a essas pessoas, quais são e como buscar seus direitos, visto gozarem de direito à informação. Esse artigo, baseia-se na experiência de um projeto de extensão que tratava do tema, e que esbarrou na falta de conhecimento e descrença dos pacientes, por saberem que o Estado, que deveria lhes garantir direitos, usurpa-os desmedidamente.

PALAVRAS-CHAVE: Direito à saúde; Portadores de câncer; Direito à informação; Extensão Universitária.

\section{ABSTRACT}

The Federal Constitution of 1988, guarantees to all citizens in its art. 196, the right to health, and it is incumbent upon the State to create policies for universal and equal access to all services that are necessary for its maintenance. However, there are certain groups that are unassisted, even if there are specific laws that address the issue, such as cancer patients. From the diagnosis, Law No. 12,732, dated November 22, 2012, guarantees the cancer patient that treatment begins in a maximum of 60 days, in addition to other rights that are conferred. Nevertheless, even with such guarantees, the State neglects itself by withdrawing from these

\footnotetext{
1 Acadêmica do curso de Direito da Universidade Federal do Tocantins, Campus Palmas. E-mail: dinah_direito@hotmail.com

2 Mestre em direito pela Universidade Católica de Brasília. Graduada em direito pela Universidade Estadual de Londrina - UEL. Professora no curso de Direito da Universidade Federal do Tocantins, Campus Palmas. Advogada. E-mail: grazielaadv@gmail.com
} 
persons the most basic rights, in the majority of cases, by the patients' own ignorance that they have their own rights. In this bias, the importance of law students, who through university extension projects, can make explicit to these people, what they are and how to seek their rights, enjoyed the right to information. This article is based on the experience of an extension project that dealt with the subject, and which ran up against the lack of knowledge and disbelief of the patients, because they knew that the State, which should guarantee them rights, usurped them unreasonably.

KEY WORDS: Right to health; cancer patients; Right to information; University Extension.

\section{INTRODUÇÃO}

No Brasil, a primeira legislação extravagante a tratar acerca dos direitos dos pacientes com câncer foi promulgada em 1988 e prevê a redução do imposto de renda para pacientes diagnosticados com neoplastia maligna, entretanto, entre a lei escrita e sua aplicação ao caso concreto, há um longo caminho.

Os pacientes com câncer têm direito desde o atendimento prioritário e totalmente gratuito, à compra de veículos adaptados e isenção total de juros para realização da compra e mais um leque de direitos, que a maioria das pessoas ignora. É sobre esse prisma que versa essa discussão, na inaplicabilidade de tais direitos à realidade da maioria dos pacientes, que por desconhecimento, impossibilidades financeiras ou emocionais, têm esses direitos ocultados e usurpados, mesmo quando os buscam.

Segundo a Organização Mundial da Saúde (OMS), o câncer mata 8,8 milhões de pessoas por ano no mundo ${ }^{3}$, no Brasil, são em média 200.000 mortes por ano, segundo o Instituto Nacional do Câncer José de Alencar Gomes da Silva (INCA), desse número, pouquíssimos tem condições de optar por um tratamento na rede particular de saúde, portanto, recorrem ao Sistema Único de Saúde (SUS), que sofre com altas demandas e pouquíssimos investimentos.

A desinformação faz com que esses pacientes padeçam pela falta de garantia dos seus direitos, um direito posto no papel sem aplicação é apenas um direito simbólico, figurativo, alegórico que para nada serve. A busca para que se chegue ao efetivo exercício de um direito é constante, primordial e necessária. A intervenção do

3 Instituto Nacional de Câncer José Alencar Gomes da Silva. Disponível em http://www.inca.gov.br/estimativa/2018/sintese-de-resultados-comentarios.asp, acesso em 24.10.2018. 
estudante de direito, com um papel social e humanitário para que essa lacuna da desinformação seja sanada, é imprescindível, principalmente, estudantes de universidades públicas estaduais e federais, tendo em vista, a contrapartida que deve ser dada para com a sociedade, que mantém por meio de seus impostos, tais universidades em pleno funcionamento.

O caminho para tanto pode ser pela extensão universitária promovida pelas universidades públicas de forma obrigatória, considerando que extensão é um dos pilares da educação pública superior, todavia, muitas vezes, essa extensão é realizada de forma aleatória e equivocada, apenas para cumprir calendário, sem preocupação alguma com papel humanista que a formação superior deve ter.

\section{DOS DIREITOS DO PACIENTE COM CÂNCER}

O direito à saúde outorgado a todos os brasileiros, constitucionalmente garantido, é um direito proeminente do princípio da dignidade da pessoa humana, de que todos indistintamente têm direito à uma saúde digna, assim, o art. 196 da Constituição Federal de 1988, preceitua:

Art. 196. A saúde é direito de todos e dever do Estado, garantido mediante políticas sociais e econômicas que visem à redução do risco de doença e de outros agravos e ao acesso universal e igualitário às ações e serviços para sua promoção, proteção e recuperação. (BRASIL, Constituição da República Federativa, 1998).

Nota-se, portanto, o papel prevalecente do Estado em agir para que o tratamento de qualquer doença, seja hábil e eficiente, no entanto, tratando-se de pacientes diagnosticados com câncer, a complexidade de tratamento e seus efeitos, requer um amparo mais significativo. Assim, há diversas legislações que tratam acerca das especificidades dos direitos desses pacientes.

A Lei no 7.713 de 22 de dezembro de 1988, estabelece a isenção do pagamento de imposto de renda para pacientes diagnosticados com neoplastia maligna, conforme 0 art. $6^{\circ}$, incisos XIV e XXI:

Art. 6o Ficam isentos do imposto de renda os seguintes rendimentos percebidos por pessoas físicas: 


\section{(...)}

XIV - os proventos de aposentadoria ou reforma motivada por acidente em serviço e os percebidos pelos portadores de moléstia profissional, tuberculose ativa, alienação mental, esclerose múltipla, neoplasia maligna, cegueira, hanseníase, paralisia irreversível e incapacitante, cardiopatia grave, doença de Parkinson, espondiloartrose anquilosante, nefropatia grave, hepatopatia grave, estados avançados da doença de Paget (osteíte deformante), contaminação por radiação, síndrome da imunodeficiência adquirida, com base em conclusão da medicina especializada, mesmo que a doença tenha sido contraída depois da aposentadoria ou reforma;

$(\ldots)$

XXI - os valores recebidos a título de pensão quando o beneficiário desse rendimento for portador das doenças relacionadas no inciso XIV deste artigo, exceto as decorrentes de moléstia profissional, com base em conclusão da medicina especializada, mesmo que a doença tenha sido contraída após a concessão da pensão.

Para tanto, o paciente precisa apresentar os laudos médicos periciais recentes que comprovem seu estado de saúde e que irão determinar o tempo de isenção, de acordo com as particularidades de cada caso.

São também garantidos ao paciente com câncer, benefícios da Previdência Social, dentre eles saque do Fundo de Garantia por Tempo de Serviço (FGTS), auxíliodoença e aposentadoria por invalidez. A Lei Federal no 8.036 de 11 de maio de 1990, pormenoriza em seus incisos XI, XII e XIV de seu art. 20, as circunstâncias em que trabalhadores portadores de doenças graves, podem realizar o saque do FGTS, in verbis:

Art. 20. A conta vinculada do trabalhador no FGTS poderá ser movimentada nas seguintes situações:

$\mathrm{XI}$ - quando o trabalhador ou qualquer de seus dependentes for acometido de neoplasia maligna.

XII - aplicação em quotas de Fundos Mútuos de Privatização, regidos pela Lei $\mathrm{n}^{\circ} 6.385$, de 7 de dezembro de 1976, permitida a utilização máxima de $50 \%$ (cinquenta por cento) do saldo existente e disponível em sua conta vinculada do Fundo de Garantia do Tempo de Serviço, na data em que exercer a opção.

XIV - quando o trabalhador ou qualquer de seus dependentes estiver em estágio terminal, em razão de doença grave, nos termos do regulamento;

O auxílio-doença e a aposentadoria por invalidez, são garantidas pela Lei no 8.213 de 24 de julho de 1991, tem direito ao auxílio-doença os filiados ao Regime Geral de Previdência Social (RGPS), que estejam impossibilitados de exercer suas funções por um período de tempo maior que 15 dias, sem levar em consideração o tempo de contribuição. 
Para que o benefício da aposentadoria por invalidez seja concedido, o paciente precisa ficar definitivamente incapacitado para o exercício de suas funções, tal concessão, encontra-se nos artigos 26, inciso II e 151 da lei supramencionada, conforme abaixo:

Art. 26. Independe de carência a concessão das seguintes prestações:

II - auxílio-doença e aposentadoria por invalidez nos casos de acidente de qualquer natureza ou causa e de doença profissional ou do trabalho, bem como nos casos de segurado que, após filiar-se ao RGPS, for acometido de alguma das doenças e afecções especificadas em lista elaborada pelos Ministérios da Saúde e da Previdência Social, atualizada a cada 3 (três) anos, de acordo com os critérios de estigma, deformação, mutilação, deficiência ou outro fator que Ihe confira especificidade e gravidade que mereçam tratamento particularizado;

Art. 151. Até que seja elaborada a lista de doenças mencionada no inciso II do art. 26, independe de carência a concessão de auxílio-doença e de aposentadoria por invalidez ao segurado que, após filiar-se ao RGPS, for acometido das seguintes doenças: tuberculose ativa, hanseníase, alienação mental, esclerose múltipla, hepatopatia grave, neoplasia maligna, cegueira, paralisia irreversível e incapacitante, cardiopatia grave, doença de Parkinson, espondiloartrose anquilosante, nefropatia grave, estado avançado da doença de Paget (osteíte deformante), síndrome da deficiência imunológica adquirida (aids) ou contaminação por radiação, com base em conclusão da medicina especializada.

Tratando de casos mais específicos, a Lei № 10.223 de 15 de maio de 2001, que altera a Lei o 9.656, de 3 de junho de 1998, assegura às pacientes portadoras de câncer de mama, que tiverem os seios parcial ou totalmente retirados, o direito à cirurgia de reconstrução mamária totalmente gratuita, nos exatos termos:

Art. 1ㅇ A Lei no 9.656, de 3 de junho de 1998, passa a vigorar acrescida do seguinte art. 10-A:

"Art. 10-A. Cabe às operadoras definidas nos incisos I e II do $\S 10$ do art. 1ㅇ desta Lei, por meio de sua rede de unidades conveniadas, prestar serviço de cirurgia plástica reconstrutiva de mama, utilizando-se de todos os meios e técnicas necessárias, para o tratamento de mutilação decorrente de utilização de técnica de tratamento de câncer."

A legislação também garante aos pacientes usuários do Sistema Único de Saúde direito ao tratamento fora do domicílio (TED) com as despesas custeadas por meio da Portaria do Ministério da saúde no 55, de 24 de fevereiro de 1999. Além disso, também garante direito ao tratamento domiciliar, nos casos em seja inviável a locomoção do paciente. 
O período entre a descoberta da neoplastia maligna e o início do tratamento, também é regulado por lei, em regra, o paciente pode esperar pelo prazo máximo de 60 dias para que o tratamento de inicie, a Lei 12.732 de 12 de novembro de 2012, regula essa determinação, aludindo:

Art. 2oO paciente com neoplasia maligna tem direito de se submeter ao primeiro tratamento no Sistema Único de Saúde (SUS), no prazo de até 60 (sessenta) dias contados a partir do dia em que for firmado o diagnóstico em laudo patológico ou em prazo menor, conforme a necessidade terapêutica do caso registrada em prontuário único.

Quitação do financiamento da casa própria, isenção do IPTU, isenção de juros em compra de veículos, direito ao uso de medicamentos em desenvolvimento, amparo social ao idoso e portador de deficiência que são diagnosticados com câncer, ação judicial prioritária, transporte municipal, intermunicipal e interestadual gratuitos, isenção do pagamento de IPVA são só mais alguns dos direitos inerentes aos pacientes com câncer, garantidos por leis federais, estaduais e municipais.

Haja vista todos os direitos supracitados, depreende-se que o que mais afeta os pacientes com câncer não é falta de direitos, mas a falta de aplicação destes, a falta de políticas públicas eficazes, que confiram a esses pacientes o mínimo de segurança em um momento tão delicado de suas vidas, o que afeta esses pacientes é a ineficiência do Estado em cumprir seu papel de garantidor de direitos e de protetor da vida dos cidadãos que vivem sob sua tutela.

\section{A OMISSÃO DO ESTADO FRENTE À GARANTIA DOS DIREITOS DOS PACIENTES COM CÂNCER}

A Constituição Federal de 1998, estabelece que é dever do Estado promover garantir o bem-estar dos cidadãos, igualdade de direitos e garantia destes. Todavia, na maior parte dos casos em que deve agir em prol daqueles que precisam, o Estado se omite e nega a essas pessoas seus direitos e prerrogativas constitucionais.

A descrença da população no Estado tem crescido cada vez mais, frente aos casos notórios de corrupção e desvios de verbas que deveriam ser investidas em setores importantes, como a saúde. 
O desgaste físico, emocional e psicológico que os pacientes portadores de câncer enfrentam, faz com que o Estado, já em posição privilegiada, se sobreponha ainda mais, deixando-os desassistidos, mesmo que a assistência social seja seu dever legalmente previsto.

O art. 194 da Constituição Federal, conceitua seguridade social como:

Art. 194. A seguridade social compreende um conjunto integrado de ações de iniciativa dos Poderes Públicos e da sociedade, destinadas a assegurar os direitos relativos à saúde, à previdência e à assistência social.

A Lei orgânica do SUS no 8.080 de 19 de novembro de 1990, também estabelece como sendo obrigação do Estado, o dever de garantir a todos os cidadãos o direito à uma saúde de qualidade, em seu art. $2^{\circ}$ estabelece que a saúde é um direito fundamental do ser humano:

Art. $2^{\circ}$ A saúde é um direito fundamental do ser humano, devendo o Estado prover as condições indispensáveis ao seu pleno exercício.

$\S 1^{\circ} \mathrm{O}$ dever do Estado de garantir a saúde consiste na formulação e execução de políticas econômicas e sociais que visem à redução de riscos de doenças e de outros agravos e no estabelecimento de condições que assegurem acesso universal e igualitário às ações e aos serviços para a sua promoção, proteção e recuperação.

Mesmo com todas as previsões legais, normas, estatutos, portarias, o que temos na prática são pessoas padecendo sem nenhuma assistência ou auxílio, desconhecendo seus direitos e garantias, e o Estado logra dessa falta de conhecimento para esconder-se e silenciosa e desumanamente afanar um dos mais básicos direitos que todos os cidadãos têm, o direito à saúde, e pior, o direito à vida.

Nesse ponto, entram as universidades públicas e seus estudantes, para tentar igualar essa relação, fornecendo a essas pessoas as informações e meios para garantir seus direitos.

\section{O PAPEL hUMANO DO ESTUdANTE DE DIREITO NA EXPLICITAÇÃO DE DIREITOS E A ÉTICA MÉDICA}


A legislação brasileira, é complexa e extensa e há pouquíssimos assuntos que ela não aborde, uma vez que o direito se molda conforme as regras e costumes da sociedade, evoluindo juntamente com ela, acompanhando suas mudanças, embora, em um ritmo mais lento. Ocorre, que a maior parte da população brasileira não conhece ou busca conhecer, seja por impossibilidade ou desinteresse, quais são seus direitos reais.

O paciente com câncer não se distancia dela realidade, muito pelo contrário, está mais próximo dela que os demais, uma vez que necessita de maior assistência em todos os sentidos, inclusive jurídico. Uma ação judicial em $1^{\underline{a}}$ instancia, segundo um levantamento realizado em 2016 pelo Conselho Nacional de Justiça (CNJ), leva em média 4 anos e 4 meses para concluída, ou seja, para que seja proferida uma sentença, para quem sofre com uma doença terminal, em muitos casos, como o câncer, esse tempo se torna uma eternidade.

Mesmo que saibam que existem direitos que Ihes são próprios, ao se deparar com a morosidade da justiça brasileira, a maior parte dos pacientes acaba desistindo de continuar ou de ingressar uma ação judicial, por não disporem de condições psicológicas para esperar ou financeira para arcar com os custos de um processo que se arrastará por anos.

Nesse sentido, a legislação estabelece a obrigatoriedade da promoção de programas de extensão universitária, que tem por objetivo primário a aproximação da população das instituições de ensino, segundo a Lei de Diretrizes e Base da Educação Nacional no 9.394 de 20 de dezembro de 1996, temos:

Art. 43. A educação superior tem por finalidade:

$\mathrm{VI}$ - estimular o conhecimento dos problemas do mundo presente, em particular os nacionais e regionais, prestar serviços especializados à comunidade e estabelecer com esta uma relação de reciprocidade;

VII - promover a extensão, aberta à participação da população, visando à difusão das conquistas e benefícios resultantes da criação cultural e da pesquisa científica e tecnológica geradas na instituição.

A Constituição Federal de 1988, também estabelece em seu art. 207, o seguinte:

Art. 207. As universidades gozam de autonomia didático-científica, administrativa e de gestão financeira e patrimonial, e obedecerão ao princípio de indissociabilidade entre ensino, pesquisa e extensão. 
Infere-se, portanto, que as universidades têm o dever de promover programas de extensão universitária que aproximem os acadêmicos da comunidade na qual estão inseridas e que as mantém através de seus impostos estabelecendo com esta uma relação de reciprocidade, no entanto, mais que um dever meramente acadêmico a extensão universitária é um dever moral e humano, independentemente da área em que seja realizada.

Os cursos de direito nas universidades, podem ter um caráter mais técnico e dogmático, que humano e social, se não alcançarem essa preocupação ou responsabilidade social. Reflete-se, que os estudantes são preparados apenas para a vida profissional de modo mecânico e são estimulados a terem esse tipo de formação desde os níveis mais baixos de ensino e é por isso, inclusive, que boa parte dos alunos das universidades acham irrelevante o estudo disciplinas como filosofia, sociologia e história durante o curso, pois são conduzidos a acreditar que devem apenas decorar leis para passar em concursos ou no exame de ordem.

Ademais, vê-se que a relação médica com seus pacientes não mais traduz-se em uma relação de absoluta autoridade, paternalista e a ela atribuído um caráter místico. Ao mesmo tempo, o direito dos pacientes à informação sobre os tratamentos e procedimentos a que serão submetidos está normatizado como dever jurídico inafastável.

A profissão médica tem sido mais democratizada, exercida por homens e mulheres e alcançando pessoas que tiveram a oportunidade de serem esclarecidas, pela educação formal, ou, alcançando pessoas simples e humildes. Esses pacientes devem ser respeitados em sua individualidade, dentro dos limites para o exercício profissional e nos propósitos humanistas trazidos pelo próprio Código de Ética Médico.

O Código de Ética Médica visa definir um regramento necessário para que essa atividade tão nobre seja orientada por princípios fundamentais, já inaugurando suas normas destacando o caráter humano e coletivo da profissão: "A Medicina é uma profissão a serviço da saúde do ser humano e da coletividade e será exercida sem discriminação de nenhuma natureza " (Código de Ética Médica, Brasil, on line). 
Aqui também reside a importância do (a) acadêmico (a) de direito, auxiliando no direito constitucional à informação sobre tratamentos e cuidados médicos, sob o prisma jurídico.

Como visto, ética e medicina são indissociáveis na origem, compreendendo-se que a atuação médica sempre foi decorrente da própria solidariedade humana. Surge daí a construção do "princípio da afeição", com a relação subjetiva fora dos estreitos limites do indivíduo. O princípio em sua origem antropológica representa, a rigor, uma estratégia de preservação da espécie ou se traduz em defesa coletiva das partes solidárias, onde o todo é maior do que a soma das partes e se destaca o princípio da sobrevivência da unidade maior (espécie) por meio da defesa da unidade menor (indivíduo) 4 .

Desde Hipócrates até a doutrina da responsabilidade civil atual, os profissionais médicos têm deveres com os pacientes. Um deles, é também o direito à informação ao paciente sobre o tratamento, efeitos colaterais, chances de cura etc. No entanto, acerca dos direitos que um paciente portador de câncer tenha, passa a ser uma responsabilidade jurídica e os atores do direito devem colaborar e atuar nesse sentido. Como também, podem esclarecer aos pacientes quais seriam danos indenizáveis, como erros médicos, não escusáveis.

Sobre a relação médico/paciente e o direito, Couto Fillho e outro (2008, p.18) destacam que o paciente merece atenção e bom trato:

A figura do paciente merece, nesse universo da responsabilidade civil médica, destaque igualmente importante. Quem é o paciente afinal? É, sem sombra de dúvida, aquela pessoa que está frágil emocionalmente em razão do mal que o aflige - seja ele qual for, grave ou não -, pois o simples fato de ter de mudar a sua rotina para procurar um atendimento médico já representa, no mínimo, uma situação desconfortável.

${ }^{4}$ Conforme monografia apresentada no curso de especialização em formulação e gestão de políticas públicas, na Universidade Estadual de Londrina, disponível em http://www.escoladegestao.pr.gov.br/arquivos/File/artigos/saude/proposta de implantacao da comissao de etica e m enfermagem.pdf, acesso em 25.10.2018. 
Os pacientes, segundo os autores, enxergam nos médicos uma "tábua de salvação" e esperam deles alívio e cura para seus sofrimentos. Contudo, há ainda benesses que os direitos previstos para alguns pacientes podem concretizar, e aí que se percebe a importância dos profissionais do direito que desde a sua formação sejam levados a se preocuparem com a humanização das relações jurídicas e querem levar essas informações importantes para quem sofre e para quem delas precisa.

O estudante de direito, como futuro operador do direito, tem a chance de mudar a realidade esmagadora de desconhecimento jurídico que assola a sociedade como um todo e a extensão é um meio para que isso acorra, todavia, a promoção da extensão universitária é feita de forma equivocada e compulsória, fazendo com que os alunos só a façam para cumprir um protocolo e obter uma nota, sem o caráter social e tampouco humano que a extensão deve ter.

Para que o modelo adotado de extensão universitária, função social acadêmica, não pareça exaustivo e desmotivador, a extensão poderia ser reforçada e considerada no curso, como uma forma de promoção de políticas que impulsionem os alunos a terem o mínimo de satisfação em estar realizando as atividades de extensão e quando estes de fato quiserem promover projetos relevantes e que, certamente, terão efetividade e continuidade, não sejam tolhidos e que encontrem nos professores e técnicos do curso e na IES, o apoio necessário para a realização de seus projetos.

É evidente o quanto acadêmicos (as) de direito são relevantes nesse comprometimento da universidade em levar conhecimento e informação às pessoas, sobretudo, a quem sofre e necessita de garantias jurídicas mínimas para continuar um tratamento de saúde de enfermidades que podem ser imensamente incapacitantes, que abalam física e emocionalmente seus pacientes. Por outro lado, retornará em ganho aos acadêmicos, uma vez que serão amadurecidos e melhor compreenderão o aspecto interdisciplinar nessa relação entre o direto e a saúde, preparando-os a lidarem com o tema, sobretudo no que concerne à responsabilidade civil do Estado, a relação com as empresas de planos de saúde, a responsabilidade dos hospitais e clínicas privados e, até mesmo, dos profissionais liberais que atuem. 


\section{DO DIREITO À INFORMAÇÃO E OS PACIENTES COM CÂNCER}

O dever do profissional médico de informar ao paciente, seja profissional liberal, seja como representante de pessoa jurídica de direito privado, seja como servidor (a) público, é fundamental e necessário, considerando o direito como um defeito na prestação de serviços médicos se houver a falha ou deficiência nessa obrigação de informar. Nesse sentido:

É fundamental se ter em mente que o direito à informação está intimamente ligado com o princípio da boa-fé objetiva e com a doutrina dos deveres anexos, acessórios ou secundários da prestação principal. A boa fé objetiva não pode ser confundida com a subjetiva. A boa fé objetiva analisa a conduta do sujeito, sendo irrelevantes os aspectos psicológicos que fizeram com que o sujeito realizasse determinada conduta. Trata-se da análise da atuação das pessoas em suas relações. José Roberto Castro Neves destaca a diferença entre boa-fé objetiva e subjetiva ao dizer que: "Enquanto a boa-fé subjetiva examina 0 conteúdo interno do ato, a crença do sujeito, a boa-fé objetiva vai averiguar o fato objetivamente, os aspectos externos do ato"5 Fontenelle (2009, on line).

Couto Filho e Souza (2008, p.35) afirmam que:

(...) não basta que não se tenha lesado o paciente em razão de um atuar falho, é fundamental que este paciente tenha sido devidamente informado sobre os possíveis riscos de ser lesionado em virtude do tratamento ao qual foi submetido, salvo se ocorrer um caso ainda não visto pela comunidade científica, vale dizer, inédito.

Vale destacar ainda, que a própria declaração universal dos direitos humanos assegura o direito à informação:

A Declaração Universal dos Direitos Humanos diz no seu artigo XIX que "Toda pessoa tem direito à liberdade de opinião e expressão; este direito inclui a liberdade de, sem interferência, ter opiniões e de procurar, receber e transmitir informações e ideias por quaisquer meios e independentemente de fronteiras. ${ }^{6}$

${ }^{5}$ Cabral, Bruno Fontenelle. Reflexões sobre o direito à informação dos pacientes no Brasil e nos Estados Unidos. Disponível em < https://jus.com.br/artigos/13851/reflexoes-sobre-o-direito-ainformacao-dos-pacientes-no-brasil-e-nos-estados-unidos>, acesso em 26.10.2018.

6 ONU, Declaração Universal Dos Direitos Humanos. Disponível em: < https://nacoesunidas.org/direitoshumanos/declaracao >. Acesso em: 25/10/2018. 
Torna-se fácil perceber o quão humano e necessário é se viabilizar projetos que atendam à concretude desse direito constitucional à informação.

\section{CONSIDERAÇÕES FINAIS}

A extensão universitária é a grande chave para a aproximação da universidade com a comunidade local, de forma a contribuir para a formação da cidadania e disseminação de conhecimentos. O objetivo é apresentar a experiência adquirida a partir da vivência enquanto estudantes de direito - conhecimento teórico - e levar informações jurídicas às pessoas que delas necessitam ( como concretizar direitos na prática, a partir da teoria compartilhada) e em grau mais avançado, alcançar a construção de novos projetos de extensão que sejam contínuos nos cursos de direito das IES e que gerem nos acadêmicos a satisfação de cumpri-los, ao mesmo tempo em que aprendem, amadurecem e se preparam de forma responsável e humanista para o futuro profissional.

Nesse contexto, tem-se que a saúde pública no Brasil apresenta problemas e o Estado, nem sempre consegue atender e conscientizar pacientes de muitos dos seus direitos garantidos legalmente. O paciente com câncer, assim como outros grupos de pessoas, que precisam de maior amparo do Estado, são os mais afetados, visto que, não há promoção de políticas públicas que os aproximem de seus direitos e os equiparem ao restante da população, a balança da justiça, como sabemos, não é igual, e sempre pesa para o lado onde há mais recursos.

A aplicabilidade de todos os direitos supraditos, é uma obrigação não só legal, mas moral, posto que, trata-se de pessoas, de serem humanos que tem direito a um mínimo de dignidade e assistência, seja ela emocional, social, psicológica ou jurídica. É estarrecedor que princípios tão básicos, devam ser sempre lembrados, porque toda pessoa, portadora ou não de neoplastia maligna, deve ter seus direitos respeitados e garantidos.

É dever do Estado, promover políticas públicas efetivas que alterem esse quadro de forma peremptória, e é papel do estudante e das universidades, lutar para que a sociedade onde estão inseridos seja uma sociedade justa e igual, seja através de uma 
formação não meramente técnica, mas humana, formando não só profissionais, formando cidadãos mais conscientes e cientes da realidade e dispostos a mudá-la, seja través da extensão de forma legítima e produtiva, com recursos e meios que façam com essa extensão perpasse o cumprimento obrigatório da grade curricular.

O direito à informação médica está contextualizado no direito constitucional à informação, conforme expresso no seu artigo 5ำ, XIV: "é assegurado a todos o acesso à informação". A informação médica está afeta à relação médico-paciente. Outra informação, também direito constitucional do paciente, é a que diz respeito à legislação que traz direitos a esses pacientes. Aí, os atores do direito devem atuar, e o alívio que o paciente espera pode estar na obtenção de um direito social previsto, que the dê condições, muitas vezes financeiras, para continuar o seu tratamento.

As pessoas acometidas pelo câncer, ainda enfrentam a falta de informação que Ihes negligenciam direitos especiais citados na legislação e só engrandece a universidade, o curso, docentes e discentes poderem auxiliar os portadores da grave doença, com palestras, mini cursos e materiais informativos para ajudar no cotidiano e para facilitar juridicamente a vida de tantos pacientes que sofrem. Entre tantos benefícios assegurados, informar-Ihes sobre o auxílio-doença, isenção de pagamento do Imposto de Renda, IPI, ICMS e IPVA, desconto na conta de luz, cirurgia de reconstrução mamária, possibilidade de quitação de imóvel, entre outros, trará esperança e um pouco de conforto para tantas pessoas e o senso de responsabilidade social e humanismo aos envolvidos em tais projetos.

Por outro lado, para que o desenvolvimento da extensão não seja sofrido demais para os (as) acadêmicos (as), estes deverão encontrar apoio em professores que abracem tais projetos e devem ser sensibilizados de que esse papel da extensão universitária traz ganhos recíprocos, para a comunidade que necessita e espera auxílio e para os próprios alunos (as) envolvidos (as), que aprenderão mais sobre o tema, sobre humanismo e sobre responsabilidade social, sentindo o quanto podem doar para a sociedade em que estão inseridos.

Da problematização "qual o sentido de obrigar os acadêmicos a promoverem extensão e não lhes dar o apoio necessário para que isso ocorra, conclui-se que a extensão deve ser praticada, isto é indiscutível e poderá ser melhorada ou qualificada, 
se o eixo fundamental do curso de direito das IES que é a garantia de direitos humanos for compreendido e sentido no coração de cada um que se envolverá no projeto. Certamente, daí virão o interesse, a técnica, a ética e o comprometimento e a criatividade, para que tudo saia do papel e cumpra os objetivos republicanos que devem orientar a cada pessoa.

\section{REFERÊNCIAS}

BARBOSA, Antonieta. Câncer, Direito e Cidadania, 15aㅡ ed. Editora Atlas, 2014.

BRASIL, Constituição da República Federativa do. BRASÍLIA, DF, 1988.

. Código de Ética Médica, Resolução CFM n. 1.246/88. Disponível em https://portal.cfm.org.br/images/stories/biblioteca/codigo\%20de\%20etica\%20medica.pdf , acesso em 25.10.2018.

. Decreto de Lei no 7713 de 22 de dezembro 1988. Imposto de Renda. BRASÍLIA, DF. Dez 1988.

. Decreto Lei no 8036 de 11 de maio de 1990. Fundo de Garantia Por Tempo de Serviço. BRASÍLIA, DF. Mai 1990.

. Decreto de Lei no 8213 de 24 de julho de 1991. Planos de Benefícios da Previdência Social. BRASÍLIA, DF. Jul. 1991.

. Decreto de Lei o 8742 de 07 de dezembro de 1993. Organização da Assistência Social. BRASÍLIA, DF. Dez 1993.

. Decreto de Lei no 9394 de 20 de dezembro de 1996. Lei de Diretrizes e Base da Educação Nacional. BRASíLIA, DF. Dez 1996.

. Decreto de Lei o 12732 de 22 de dezembro de 2012. Primeiro tratamento de paciente com neoplasia maligna comprovada e prazo para seu início. BRASÍLIA, DF. Nov. 2012.

, Ministério da Saúde. Portaria no 55 de 24 de fevereiro de 1999. Tratamento Fora de Domicilio no Sistema Único de Saúde - SUS. BRASÍLIA, DF. Fev. 1999.

BRETAS, Valéria. Quanto tempo a Justiça do Brasil leva para julgar um processo? Disponível em: https://exame.abril.com.br/brasil/quanto-tempo-a-justica-do-brasil-levapara-julgar-um-processol, acesso em 25/09/2018.

CABRAL, Bruno Fontenelle. Reflexões sobre o direito à informação dos pacientes no Brasil e nos Estados Unidos. Disponível em < 
https://jus.com.br/artigos/13851/reflexoes-sobre-o-direito-a-informacao-dos-pacientesno-brasil-e-nos-estados-unidos $>$, acesso em 26.10.2018.

COUTO FILHO, Antônio Ferreira e SOUZA, Alex Pereira. Responsabilidade Civil Médica e Hospitalar. Editora Lúmen Juris. Rio de Janeiro: 2008

Instituto Nacional de Câncer José Alencar Gomes da Silva. Disponível em <http://www.inca.gov.br/estimativa/2018/sintese-de-resultados-comentarios.asp>, acesso em 24.10.2018.

ONU, Declaração Universal Dos Direitos Humanos. Disponível em: < https://nacoesunidas.org/direitoshumanos/declaracao/>. Acesso em: 25/10/2018. 